\title{
Central Nervous System Infiltration in Acute Lymphoblastic Leukemia in a Dog
}

\author{
Giovana Scuissiatto de Souza ${ }^{1}{ }^{1}$, Gabriela Oliveira da Paz Augusto Pinto ${ }^{2}{ }^{2}$, \\ Weslley Junior de Oliveira ${ }_{(i)}^{1} \&$ Rosangela Locatelli-Dittrich ${ }_{(i)}^{3}$
}

\begin{abstract}
Background: Acute lymphoblastic leukemia (ALL) is a malignant neoplasia in which there is proliferation of lymphoid progenitor cells in the bone marrow, blood, and extramedullary sites. This disorder has a fast and progressive development; in dogs, cases of infiltration of ALL cells in the central nervous system (CNS) are uncommon and rare. Diagnosis can be achieved with the help of the clinical history and physical, radiographic, hematological, myelographic, and cerebrospinal fluid (CSF) tests in patients with or without neurological clinical signs. The present report aims to describe a case of ALL and the presence of lymphoblasts in the CSF of a dog with neurological clinical signs.

Case: An 8-year-old Lhasa Apso dog was examined at the Veterinary Hospital of Universidade Federal do Paraná, Curitiba campus. At the physical examination, the animal exhibited apathy and paralysis of pelvic limbs, which progressed to tetraplegia. Abdominal palpation revealed presence of hepatosplenomegaly and absence of lymphadenomegaly. No alterations were observed in radiographs of the cervical, thoracic or lumbar spine. A complete blood count revealed presence of non-regenerative anemia (hematocrit $=22 \%$ ), extreme lymphocytosis $(185,229$ cells/ $\mu \mathrm{L})$, lymphoblasts at a level of $72 \%$ (133,364 cells $/ \mu \mathrm{L})$, and thrombocytopenia $(66,000$ platelets $/ \mu \mathrm{L})$. The biochemical tests revealed increased alkaline phosphatase ( $859 \mathrm{IU} / \mathrm{L})$. The levels of alanine aminotransferase, creatinine, urea, total protein, albumin, and globulin were normal. The diagnosis of ALL was achieved with the help of a myelogram. The myelogram findings included 39\% of mature lymphocytes and 59\% of lymphoblasts exhibiting large size, spherical shape, poorly delimited borders, with a high nucleus/cytoplasm ratio, marked cytoplasmic basophilia, and 2 to 3 evident nucleoli; metarubricytes (1\%) and promyelocytes $(0.6 \%)$ were also observed. The CSF contained an increased number of nucleated cells $(27 \mathrm{cells} / \mu \mathrm{L})$ comprising lymphocytes (43\%), macrophages (33\%), and segmented neutrophils (24\%). Of the 11.6 lymphocytes per $\mu \mathrm{L}$ of CSF, 8.1 were lymphoblasts, which indicates infiltration of ALL cells in the CNS. The animal died one day after collection of bone barrow and CSF.

Discussion: Relevant alterations observed in this case included the neurological signs caused by the infiltration of neoplastic cells in the CNS, severe leukocytosis and lymphocytosis, with large amounts of lymphoblasts in the blood and predominance of lymphoblasts in the bone marrow, which are alterations typically found in ALL. The animal also exhibited non-regenerative anemia and thrombocytopenia, which were secondary to infiltration of leukemic cells in the bone marrow. The CSF exhibited pleocytosis ( 27 cells $/ \mu \mathrm{L}$ ), and $30 \%$ of the cells observed were lymphoblasts. Lymphoblast infiltration in the CNS of leukemic dogs is rare, and other studies have reported absence of neurological signs or neurological signs different from those observed in the present study. CSF analysis in indicated in cases of leukemia to assess leukemic cell infiltration in the CNS. In the case reported here, the plasma level of alkaline phosphatase was increased (859 IU/L) as a consequence of hepatomegaly and hepatic cholestasis. ALL is a very aggressive, proliferative neoplasia, and the resulting lymphoblasts infiltrated the CNS of the animal. In cases of ALL, performing complete blood count, myelogram, and CSF analysis is indicated whether the patients exhibit neurological signs or not.
\end{abstract}

Keywords: bone marrow, lymphocytes, cerebrospinal fluid, lymphoproliferative diseases, lymphoblasts.

Descritores: medula óssea, linfócitos, líquido cefalorraquidiano, doenças linfoproliferativas, linfoblastos. 


\section{INTRODUÇÃO}

A leucemia linfoblástica aguda (LLA) é uma neoplasia rara em cães, de origem hematopoética, caracterizada pela autorreplicação desordenada de linfoblastos na medula óssea e sangue $[5,6,8]$. É relatada em cães jovens e de meia-idade [3,6]. Os sinais clínicos incluem dor generalizada, anorexia, letargia e hepatoesplenomegalia, devido a replicação de linfoblastos na medula óssea, diminuição da produção de células hematopoiéticas precursoras normais e infiltração de linfoblastos nos tecidos [6,11]. A infiltração de linfoblastos no sistema nervoso central (SNC) é incomum em cães e até o presente verificou-se um relato em cão com sinais neurológicos com LLA. A metástase para o SNC pode causar sequelas como paralisia de membros, ataxia, episódios de convulsões entre outros sinais neurológicos [1,7,11].

O diagnóstico da LLA é realizado pelo histórico, sinais clínicos e exames como hemograma e mielograma, e quando são observados no mínimo $25 \%$ de linfoblastos na medula óssea [3,5]. A imunofenotipagem por citometria de fluxo permite identificar a origem dessas células. A técnica utiliza anticorpos monoclonais direcionadas às moléculas das células. A LLA pode ser de origem de células T ou B. No Brasil, ainda não é conhecido o fenotípico mais comum. Nos Estados Unidos, estudos mostram que o fenótipo com maior frequência na LLA em cães é o B $[5,6,12]$.

As leucemias agudas são invasivas e não responsivas ao tratamento, com prognóstico desfavorável $[2,3,10]$. Este relato objetivou descrever um caso de LLA em cão com sinais neurológicos decorrentes da infiltração de células neoplásicas no SNC, demonstrando a importância da análise citológica do líquido cefalorraquidiano nas leucemias.

\section{CASO}

Uma cadela da raça Lhasa Apso, 8 anos, foi atendida no Hospital Veterinário da UFPR com quadro de dispneia, apatia, aumento de volume abdominal e paralisia de membros pélvicos, evoluindo para tetraplegia. Ao exame físico, foi constatada ausência do reflexo de retirada, ausência do reflexo patelar e isquiático. $\mathrm{O}$ animal apresentou temperatura de $38,3^{\circ} \mathrm{C}$, pressão arterial $157 \mathrm{mmHg}$, pulso forte e mucosas hipocoradas. Foi constatada hepatoesplenomegalia na palpação abdominal e a ausência linfoadenomegalia. Optou-se pela realização do exame ultrassonográfico, o qual verificou-se pequena quantidade de efusão peritoneal e hepatoesplenomegalia, com deslocamento caudal do rim esquerdo. Nas radiografias da coluna cervical, torácica e lombar, não foram observadas alterações. Foi realizada a colheita de sangue em tubo a vácuo com anticoagulante EDTA ${ }^{1}$ e tubo a vácuo sem anticoagulante $^{1}$ para realização de hemograma e bioquímicos, respectivamente. No hemograma verificou-se leucocitose $(187.100 / \mu \mathrm{L})$, neutropenia $(1.871 / \mu \mathrm{L})$, linfocitose (185.229/ $\mu \mathrm{L})$, e $72 \%$ de linfoblastos $(133.364 / \mu \mathrm{L})$ com nucléolos evidentes (Figura 1), indicativo de LLA. Observou-se também anemia macrocítica hipocrômica (hematócrito: $22 \%$ ), e importante trombocitopenia $(66.000 / \mu \mathrm{L})$. A contagem de reticulócitos foi de $0 \%$, resultando em anemia não regenerativa.

Nos exames bioquímicos verificou-se aumento da Fosfatase Alcalina (859 UI/L). Os outros resultados foram: Alanina Aminotransferase (ALT) $(16 \mathrm{U} / \mathrm{L})$, Creatinina (1,0 mg/dL), Ureia (59 mg/dL), Proteína Total (5,4 g/dL), Albumina (2,9 g/dL) e Globulina (2,5 g/dL), resultados normais. Devido a linfocitose extrema e a presença de linfoblastos no sangue, foi realizado o aspirado de medula óssea para mielograma. Na sequência, foi realizada a coleta de líquor, devido a presença de sinais neurológicos. A cadela foi induzida à anestesia com Fentanestâ ${ }^{2}(5 \mathrm{mg} / \mathrm{kg})$ associado à Midazolan ${ }^{3}$ $(0,3 \mathrm{mg} / \mathrm{kg})$ e manutenção anestésica com Propovanâ ${ }^{2}$ $(4 \mathrm{mg} / \mathrm{kg})$. Após antissepsia, o aspirado de medula óssea foi coletado com agulha hipodérmica $(40 \times 16 \mathrm{~cm})$ e seringa com EDTA na crista ilíaca. A amostra de medula óssea foi transferida para uma placa de Petril e as espículas medulares foram coletadas para confecção das lâminas pelo método de "squash". As lâminas com medula óssea foram secas ao ar e coradas pelo método May Grünwald-Giemsa ${ }^{4}$. O líquido cefalorraquidiano foi coletado da cisterna magna com agulha hipodérmica $(40 \times 16 \mathrm{~cm})$ e seringa, e foi armazenado em tubo tipo eppendorf estéril1. No líquor foi realizado exame físico, químico e citológico. A lâmina foi corada com pelo método May Grünwald-Giemsa ${ }^{4}$. No mielograma foram avaliadas 500 células, sendo observados na série eritrocítica 5 (1\%) metarrubrócitos (valor de referência: $15,3 \%)$ e na série granulocítica $3(0,6 \%)$ prómielócitos (valor de referência: 1,3\%); 197 (39\%) linfócitos maduros pequenos e 295 (59\%) linfoblastos grandes (valor de referência: 0,2\%), esféricos, com bordas mal definidas, alta proporção núcleo/citoplasma e basofilia citoplasmática acentuada, cromatina fina e granular/ 
reticular, com 2 a 3 nucléolos evidentes (Figura 2). Observou-se anisocitose e anisocariose marcantes nos linfoblastos; e 9 figuras de mitose.

O líquido cefalorraquidiano estava incolor e translúcido, com densidade 1,006, proteína de 38 $\mathrm{mg} / \mathrm{dL}$ e glicose $116 \mathrm{mg} / \mathrm{dL}$, celularidade de $27 / \mu \mathrm{L}$ de células nucleadas e 132/ $\mu \mathrm{L}$ eritrócitos. No exame citológico, constatou-se predomínio de linfócitos (43\%), seguido de macrófagos $(33 \%)$ e neutrófilos segmentados (24\%). Dos 11,6/ $\mathrm{LL}$ de linfócitos, 8,1/ $\mu \mathrm{L}$ eram linfoblastos. Foram observadas também raras hemácias e uma figura de mitose. Não foi realizado a citometria de fluxo, portanto não foi possível distinguir se a LLA era de linfócitos T ou B.

No dia seguinte ao internamento, houve o agravamento do quadro clínico e neurológico, e a cadela foi a óbito.

\section{DISCUSSÃO}

As alterações mais importantes no presente caso foram a leucocitose $(187.100 / \mu \mathrm{L})$, linfocitose $(185.229 / \mu \mathrm{L})$, presença de $72 \%$ de linfoblastos no sangue, predomínio de 59\% de linfoblastos na medula óssea e de $30 \%$ no líquido cefalorraquidiano, alterações presentes na LLA com infiltração de células neoplásicas no sistema nervoso central $[3,5,10]$. Observou-se anemia não regenerativa (hematócrito 22\%) e trombocitopenia $(66.000 / \mu \mathrm{L})$, devido à infiltração de células leucêmicas na medula óssea [3]. Na literatura foi encontrado um caso de LLA com infiltrado de linfoblastos no SNC [11], mas com diferenças em algumas alterações hematológicas. No caso da literatura, um cão de 6 anos com anemia não regenerativa leve (hematócrito 35\%), leucopenia $(4.400 / \mu \mathrm{L})$, lin-

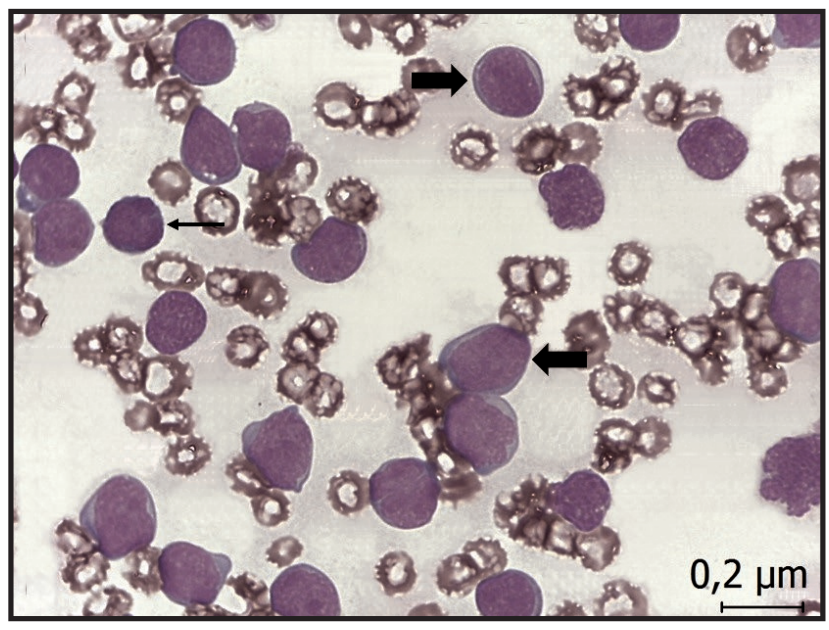

Figura 1. Presença de linfoblastos grandes, com nucléolos evidentes (seta maior) e linfócitos (seta menor) no sangue periférico de cão com leucemia linfoblástica aguda. [May-Grünwald-Giemsa; Obj. 40x]. fopenia $(616 / \mu \mathrm{L})$, presença de $1 \%$ de linfoblastos no sangue e trombocitopenia $(96.000 / \mu \mathrm{L})$ [11]. No líquido cefalorraquidiano os autores encontraram $87 \%$ de linfoblastos, em $86 / \mu \mathrm{L}$ células nucleadas, uma maior celularidade do que observado no presente estudo [11]. Os sinais neurológicos foram variáveis, o cão do presente caso teve paralisia de membros pélvicos, evoluindo para tetraplegia, e no estudo mencionado o autor descreveu ataxia, tetraparesia e opistótono [11].

A infiltração de células neoplásicas no SNC de cães foi relatada nas leucemias mielomonocítica aguda [1], megacarioblástica aguda [7] e mielóide crônica [4]. Diferente do presente caso, nos cães com 1 ano de idade e leucemia megacarioblástica aguda [7], e com 10 anos e leucemia mieloide crônica [4], o diagnóstico de infiltração no sistema nervoso central foi realizado no exame histopatológico post mortem do cérebro. No primeiro caso [7], o cão não apresentava sinais neurológicos, e no segundo [4], os sinais eram cegueira e episódios de convulsões incontroláveis. Em outro relato, de leucemia mielomonocítica aguda [1] em cão, as células leucêmicas foram observadas no líquido cefalorraquidiano ante mortem, e os sinais neurológicos eram paralisia facial bilateral, mandibular e fotofobia. Os sinais neurológicos nos cães com leucemia e infiltrado de células leucêmicas no SNC foram variáveis.

No presente estudo o animal também apresentou hepatoesplenomegalia, que pode ser observada em alguns casos LLA pela infiltração de linfoblastos nesses orgãos [8,9,11]. Nos exames bioquímicos, a única anormalidade foi o aumento da fosfatase alcalina

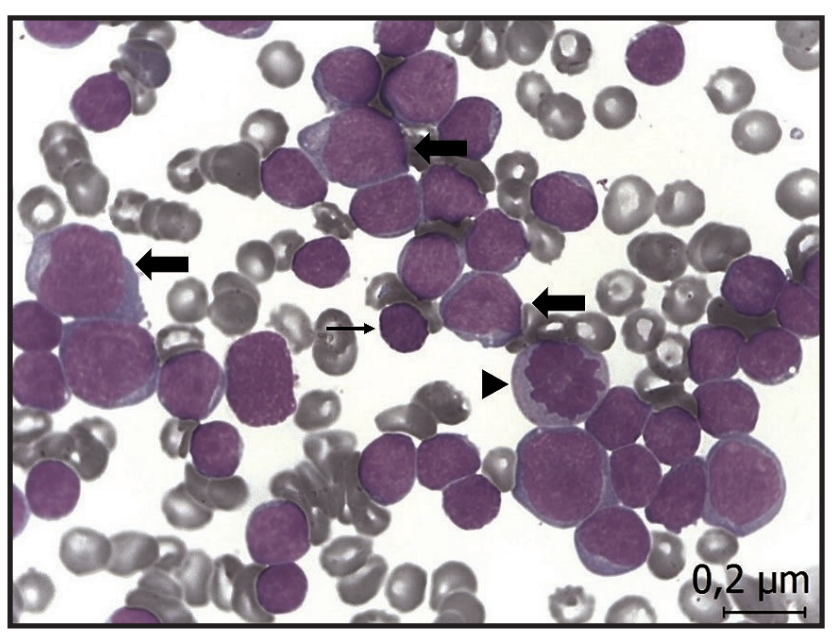

Figura 2. Predomínio de linfoblastos grandes, esféricos, com bordas mal definidas, alta proporção núcleo/citoplasma e basofilia citoplasmática acentuada, cromatina granular, com dois a três nucléolos evidentes (seta maior) na medula óssea de cão com leucemia linfoblástica aguda. Observar os linfócitos maduros e pequenos (seta menor) e figura de mitose (ponta da seta). [May-Grünwald-Giemsa; Obj. 40x]. 
(859 UI/L), devido a hepatomegalia que resultou em colestase hepática. A linfoadenomegalia não estava presente, o que ajudou a diferenciar a LLA do linfoma em estágio V. A linfoadenopatia é ausente ou discreta na LLA, e no linfoma estágio $\mathrm{V}$ é grave $[3,8]$.

Nos poucos relatos de LLA, a idade dos animais foi de 4 a 7 anos, e no presente caso a idade da cadela era de 8 anos $[3,8,9]$. O animal foi a óbito antes do tratamento quimioterápico, confirmando a gravidade e prognóstico ruim da LLA, com a piora do quadro devido ao comprometimento do SNC.

A leucemia linfoblástica aguda é uma neoplasia altamente invasiva que pode infiltrar o sistema nervoso central, sendo indispensável a realização do hemograma, mielograma e exame do líquido cefalorraquidiano em pacientes com ou sem sinais neurológicos.

\section{MANUFACTURERS}

${ }^{1}$ Cral Artigos Para Laboratório Ltda. Cotia, SP, Brazil

${ }^{2}$ Cristália Produtos Químicos Farmacêuticos Ltda. Itapira, SP, Brazil.

${ }^{3}$ Laboratório Teuto Brasileiro S.A. São Paulo, SP, Brazil.

${ }^{4}$ Newprov Produtos para Laboratório Ltda. Pinhais, PR, Brazil.

Declaration of interest. The authors report no conflicts of interest. The authors alone are responsible for the content and writing of paper.

\section{REFERENCES}

1 Christopher M.M., Metz A.L., Klausner J., Polzin D. \& Hayden D.W. 1986. Acute myelomonocytic leukemia with neurologic manifestations in the dog. Veterinary Pathology. 23(2): 140-147.

2 Comazzi S., Martini V., Riondato F., Poggi A., Stefanello D., Marconato L., Albonico F. \& Gelain M.E. 2017. Chronic lymphocytic leukemia transformation into high grade lymphoma: a description of Richter's syndrome in eight dogs. Veterinary and Comparative Oncology. 15(2): 366-373.

3 Dobson J., Villiers E. \& Morris J. 2006. Diagnosis and management of leukaemia in dogs and cats. In Practice. 28(1): 22-31.

4 Grindem C.B., Stevens J.B., Brost D.R. \& Johnson D.D. 1992. Chronic myelogenous leukaemia with meningeal infiltration in a dog. Comparative Hematology International. 2(3): 170-174.

5 Harvey J.W. 2012. Disorders of Bone Marrow. In: Veterinary Hematology - A Diagnostic Guide and Color Atlas. Gainnesville: Elsevier, pp.298-300.

6 Presley R.H., Mackin A. \& Vernau W. 2006. Lymphoid leukemia in dogs. Compendium. 28(12): 831-849.

7 Rochel D., Abadie J., Robveille C., Déqueant B., Dagher E., Roux F. \& Jaillardon L. 2018. Thrombocytosis and central nervous system involvement in a case of canine acute megakaryoblastic leukemia. Veterinary Clinical Pathology. 47(3): 363-367.

8 Silva L., Dietze W., Costa C.A.S., Allgayer M.C. \& Witz M.I. 2016. Leucemia linfoblástica aguda e aspectos microscópicos - relato de caso. Revista Veterinária em Foco. 14(1): 3-9.

9 Tomaz K.L.R., do Vale A.M. \& Soto-Blanco B. 2013. Leucemia linfoblástica aguda em um cão. Acta Scientiae Veterinariae. 41(Suppl 1): 19.5p.

10 Tomiyasu H., Doi A., Chambers J.K., Goto Koshino Y., Ohmi A., Ohno K. \& Tsujimoto H. 2018. Clinical and clinicopathological characteristics of acute lymphoblastic leukaemia in six cats. Journal of Small Animal Practice. 59(12): $742-746$.

11 Vernau K.M., Terio K.A., Lecouteur R.A., Berry W.L., Vernau W., Moore R.E. \& Samii V.F. 2000. Acute B cell lymphoblastic leukemia with meningeal metastasis causing primary neurologic dysfunction in a dog. Journal of Veterinary Internal Medicine. 14(1): 110-115.

12 Weiss D.J. 2010. Hematologic Neoplasia. In: Weiss D.J. \& Wardrop K.J. (Eds). Schalm's Veterinary Hematology. 6th edn. Pullman: Wiley-Blackwell, pp.491-495. 